\title{
RFQ AND IH ACCELERATORS FOR THE NEW EBIS INJECTOR AT BNL*
}

\author{
A. Schempp, U. Ratzinger, R. Tiede, C. Zhang; IAP, Univ. Frankfurt, Germany \\ J. Alessi, D. Raparia, L. Snydstrup; BNL, Upton NY, U.S.A
}

\section{Abstract}

The new EBIS preinjector at BNL will accelerate ions from the EBIS source with specific mass to charge ratio of up to 6.25 , from $17 \mathrm{keV} / \mathrm{u}$ to $2000 \mathrm{keV} / \mathrm{u}$ to inject into the Booster synchrotron, expanding experimental possibilities for RHIC and NASA experiments. The properties of the RFQ and IH accelerators and the status of the project will be discussed.

\section{INTRODUCTION}

Availability for beams for high energy heavy ion physics is limited by the properties and performance of the accelerator chain especially the low energy part, where beam intensities and emittances are set.

At RHIC the injector consists of a Tandem whose beam is transported to the AGS. The limitations of that injector, a combination of a dc, low beam current heavy ion machine with a typical pulsed proton high energy machine are obvious. Starting with negative ions, the mass range is also limited.

Plans for a new injector making use of the new developments of ion sources as well as rf-linacs have been discussed for a number of years. Now that modern injector scheme is being set up at BNL, which will lead to more reliable operation and improved capability especially for the RHIC and NSRL programs (1).

The EBIS ion source is perfectly matched to the operation pattern with its pulsed beam of highly charged ions. The RFQ accepts a low energy heavy ion beam, and bunches and accelerates it with high efficiency and low emittance growth (2). The IH structure has been applied for heavy ion machines e.g. at GSI and CERN which have demonstrated operation with very high gradients resulting in a very efficient compact ion injector for a Synchrotron $(3,4)$

Fig. 1 shows a layout of the new heavy ion injector linac with total length of appr. $12 \mathrm{~m}$, which will provide ions with $2 \mathrm{MeV} / \mathrm{u}$ for a mass to charge ratio of up to $\mathrm{A} / \mathrm{q}=6.25$

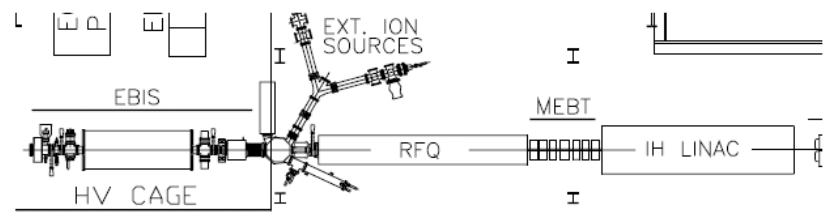

Figure 1: Layout of the EBIS Linac at BNL

\section{RFQ}

The RFQ for the new EBIS-linac at BNL accepts highly charged ions from the EBIS ion source with energy of $17 \mathrm{keV} / \mathrm{u}$ and ion currents of up tp $10 \mathrm{~mA}$. The operation frequency will be $100.625 \mathrm{MHz}$.

\section{Beam Dynamics}

The beam dynamics design does an adiabatic variation of the RFQ parameters to shape, bunch and accelerate the beam (5). We optimized the design to get a rather short structure with $\mathrm{L}_{\mathrm{RF}}=3.1 \mathrm{~m}$ with moderate electrode voltages of $\mathrm{U}_{\mathrm{Q}}=70 \mathrm{kV}$.

Table 1: RFQ Beam Dynamics Design Parameters

\begin{tabular}{|l|l|}
\hline Frequency & $100.625 \mathrm{MHz}$ \\
\hline Input energy & $17 \mathrm{keV} / \mathrm{u}$ \\
\hline Output energy & $0.3 \mathrm{MeV} / \mathrm{u}$ \\
\hline Mass to charge ratio & 6.25 \\
\hline Beam current & $10 \mathrm{~mA}$ \\
\hline Outp trans. emitt rms norm. $90 \%$ & $<0.38 \pi \mathrm{mm} \mathrm{mrad}$ \\
\hline Output long. emittance $90 \%$ & $<220 \mathrm{deg} \mathrm{keV/u}$ \\
\hline Transmission & $98 \%$ \\
\hline Electrode voltage & $70 \mathrm{kV}$ \\
\hline RFQ length & $3.1 \mathrm{~m}$ \\
\hline Cell number & 191 \\
\hline Aperture min - max & $2.96-5.25 \mathrm{~mm}$ \\
\hline
\end{tabular}

Results of particle dynamics simulations show the RFQ output transmission and emittances for different beam input emittances and currents show low emittance growth and very high transmission also for $\mathrm{I}=10 \mathrm{~mA}$

Table 2: RFQ Beam Emittances

\begin{tabular}{|c|c|c|c|}
\hline $\begin{array}{l}\mathcal{E}_{\text {in }}^{\text {trans.,un., real }} \\
{[\pi \mathrm{mm}-\mathrm{rad}]}\end{array}$ & $\begin{array}{l}\text { Transm. } \\
{[\%]}\end{array}$ & \begin{tabular}{|l}
$\varepsilon_{\text {out }}{ }^{2, r m s}$ \\
{$[\mathrm{MeV}-\mathrm{deg}]$} \\
$100 \%$
\end{tabular} & \begin{tabular}{|l}
$\varepsilon_{\text {out }}{ }^{x y, \text { rms }}$ \\
{$[\pi \mathrm{mm} \mathrm{mrad}]$} \\
$100 / 90 \%$ \\
\end{tabular} \\
\hline $0.05790 \mathrm{I}=0$ & 99.0 & 0.284 & $0.064 / 0.0271$ \\
\hline $0.08685 \mathrm{I}=10$ & 98.7 & 0.243 & $0.09 / 0.038$ \\
\hline $0.11580 \mathrm{I}=0$ & 98.4 & 0.27 & $0.126 / 0.053$ \\
\hline $0.11580 \mathrm{I}=10$ & 98.7 & 0.33 & $0.15 / 0.060$ \\
\hline
\end{tabular}

Beam dynamics simulations have been done with Parmteqm Vers.3.07. This allows applying a CrandallOutput cell with low divergence of the beam. The final design has good emittances in both axial and radial direction, a very high transmission.

*Work supported by the US Department of Energy and the National Aeronautic and Space Administration. 
The beam dynamics design is very flexible, it allows rather large variations of the input beam parameters and has good output beam quality.

$100.62 \mathrm{Asz}, q=1.0, \mathrm{al}=6.25000, \mathrm{i}=10.0 \mathrm{~A}$, BNL-RFQ-CZ10
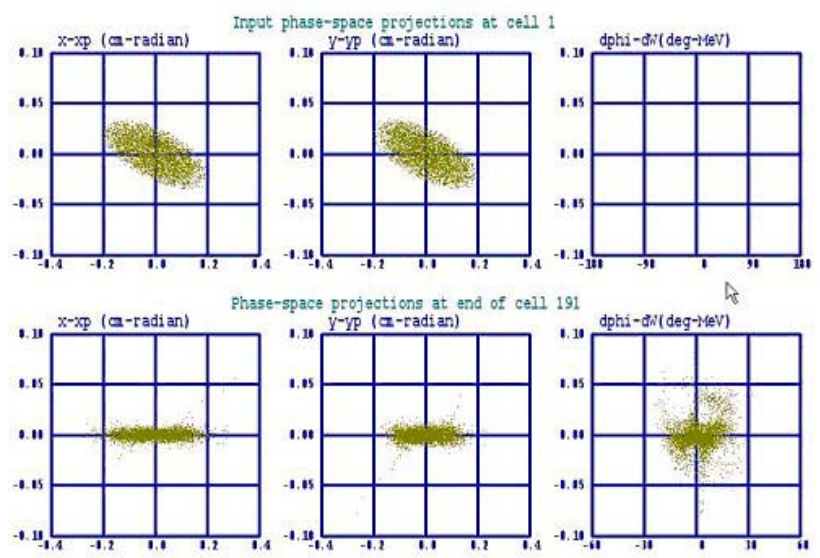

Figure 2: RFQ emittances for $\mathrm{I}=10 \mathrm{~mA}$

\section{4-Rod-RFQ-Structure}

The 4-Rod-RFQ consists of a chain of $\lambda / 2$ resonators which are operated in $\pi$-0-mode, to have opposite voltage on the adjacent electrodes and constant voltage along the RFQ. It is possible to describe the basic cell of the 4-Rod-RFQ as a capacitively loaded line, at which the electrodes are the capacity and the stems the inductivity resp. the short line.

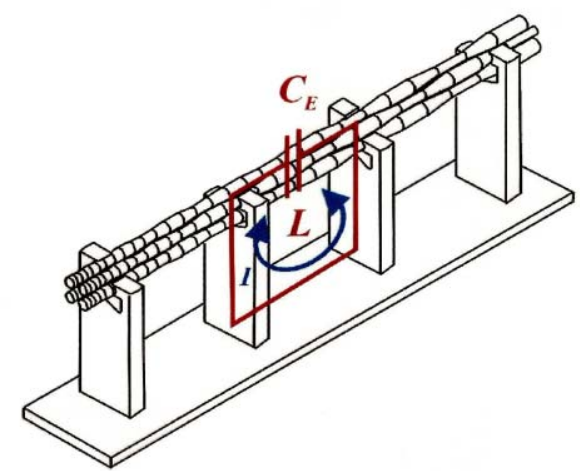

Figure 3: Basic cell of the 4-Rod RFQ structure

Table 3: 4 Rod Structure Parameters

\begin{tabular}{|l|l|}
\hline 4-Rod-RFQ & $100.625 \mathrm{MHz}$ \\
\hline Tank diameter & $350 \mathrm{~mm}$ \\
\hline Tank length & $3100 \mathrm{~mm}$ \\
\hline Beam axis height & $147 \mathrm{~mm}$ \\
\hline Stem number & 20 \\
\hline Stem distance & $158 \mathrm{~mm}$ \\
\hline Stem thickness & $10 \mathrm{~mm}$ \\
\hline Aperture & $5.2-2.96 \mathrm{~mm}$ \\
\hline Modulation factor & $1-1.99$ \\
\hline
\end{tabular}

Based on MWS-simulations and experimental results of similar RFQs the structure power for the EBIS-RFQ is 04 Hadron Accelerators in the plane between the stems. The 3-1/8" power line will be fed in by a central coupling loop.

The RFQ-cavity is made out of a $5 \mathrm{~cm}$ thick wall tube, copper plated, with inner diameter of $350 \mathrm{~mm}$. The resonant insert has a cooled base plate and solid stems and vane-electrodes. The support stand structure is $70 \mathrm{~cm}$ wide and allows horizontal adjustment.

The mechanical design is very stiff, avoids much welding for stress free, precise basic structure and by the use of the top lid allows easy installation, alignment, inspection and maintenance.

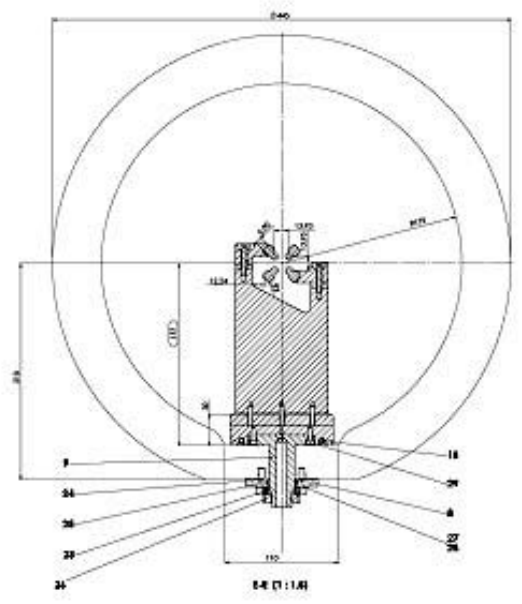

Figure 4: BNL 4-Rod RFQ Cross section

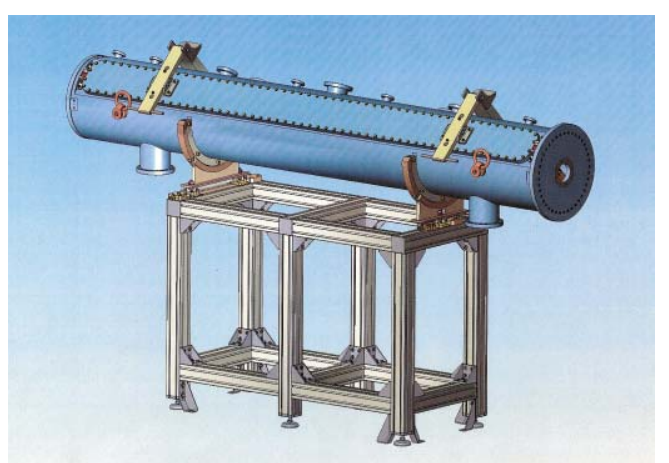

Figure 5:BNL 4-Rod RFQ set up

\section{IH-DRIFT TUBE LINAC SECTION}

An Inter-digital H-mode drift tube linac (IH-DTL) with KONUS beam dynamics (6) has been chosen as a second stage of acceleration behind of the RFQ. Table 4 shows the linac design parameters. The design current of $10 \mathrm{~mA}$ will be available for lighter ions only, but it was chosen for the beam dynamics design in order to properly consider the space charge effects.

One option for the MEBT has two quadrupole doublets and the buncher located between. Starting from the Parmteqm particle distribution calculated at the RFQ output, now an alternative compact MEBT was designed. It consists of a buncher and one quadrupole triplet only, leaving enough space for diagnostics and beam steering. 
Table 4. Main parameters of IH-DTL required for RHIC injection

\begin{tabular}{|l|l|l|}
\hline Charge-to-mass ratio & $\mathrm{Q} / \mathrm{A}$ & $0.16-1.0$ \\
\hline Operating frequency & $\mathrm{MHz}$ & 100.625 \\
\hline Input energy & $\mathrm{MeV} / \mathrm{u}$ & 0.3 \\
\hline Output energy & $\mathrm{MeV} / \mathrm{u}$ & 2.0 \\
\hline Beam current & $\mathrm{mA}$ & $0-10$ \\
\hline Cavity length & $\mathrm{m}$ & $>2.5$ \\
\hline $\begin{array}{l}\text { Transverse output emittance } \\
\text { (norm, 90\% effective) }\end{array}$ & $\mathrm{mm} * \mathrm{mrad}$ & $0.6 \pi$ \\
\hline Output energy spread $(90 \%)$ & $\mathrm{keV} / \mathrm{u}$ & \pm 1.7 \\
\hline Transmission & $\%$ & 100 \\
\hline Maximum repetition rate & $\mathrm{Hz}$ & 5 \\
\hline Eff. shunt impedance & $\mathrm{M} \Omega / \mathrm{m}$ & 253 \\
\hline
\end{tabular}

The parameters of the IH tank itself have been further optimized with respect to the previous designs. Realistic particle distributions at the RFQ output for zero and 10 $\mathrm{mA}$ beam currents were used for the IH-DTL simulations. These distributions correspond to the RFQ-design described above.

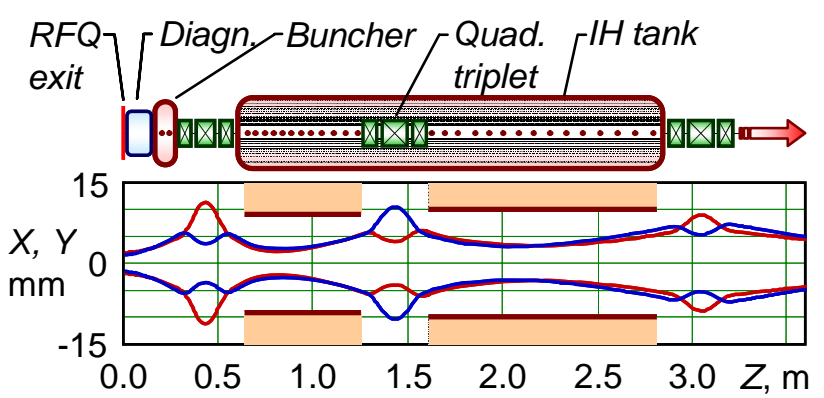

Figure 6: Array of MEBT and IH-cavity in the presented design.

Fig. 6 shows the $98 \%$ transverse beam envelopes at 10 $\mathrm{mA}$ beam current. An important parameter for efficient injection into the booster ring is the energy spread of the injected linac beam. With an additional buncher, located $5.5 \mathrm{~m}$ downstream behind the IH-cavity, the calculated energy spread is $\pm 1.7 \mathrm{keV} / \mathrm{u}$ for $90 \%$ of the beam particles (Fig. 7).

The rms emittance growth rates at full beam current are about $30 \%$ in all three planes. Especially, the longitudinal emittance along the transport line into the booster has to be carefully matched at full beam current.

\section{STATUS}

The RFQ design has been fixed, the RFQ tank is now being manufactured. RFQ inserts will be ready in September for mechanical alignment and rf-tuning.

The beam dynamics design along MEBT, IH and down to the booster is being fixed now, call for tenders for the IH cavity is prepared.

\section{REFERENCES}

[1] J. Alessi et al., "Status of the EBIS Project at Brookhaven", Proc. of the 2006 LINAC Conf., Knoxville, Tennessee, USA, p.385.

[2] A. Schempp "New developments in High Duty Cycle High Current RFQs" Linac 02, Korea,p541

[3] N. Angert et al., "The IH Linac of the CERN Lead Injector", Proc. of the 1994 LINAC Conf., Tsukuba, Japan, p.743.

[4] U. Ratzinger, "The New High Current Ion Accelerator at GSI and Perspectives for Linac Design Based on H-mode Cavities", Proc. of the 2000 EPAC Conf., Vienna, p.98.

[5] A. Schempp, "Design of Compact RFQs", Proc. of the 1996 LINAC Conf., Geneve, p.53.

[6] U. Ratzinger, "The IH Structure and its Capability to Accelerate High Current Beams", Proc. of the 1991 PAC Conf., San Francisco, CA, p.567.
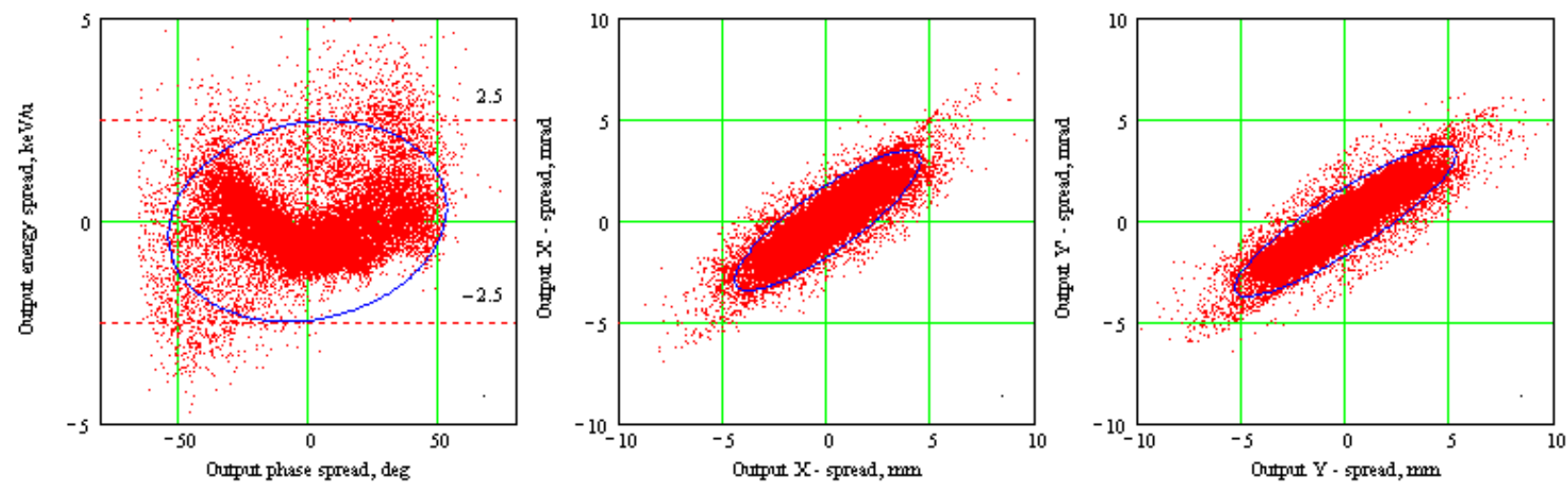

Figure 7: Particle distributions $5.5 \mathrm{~m}$ behind of the IH-cavity (after rebuncher) for a $10 \mathrm{~mA}$ and $2 \mathrm{MeV} / \mathrm{u}$ beam. 